\title{
THE COMPATIBILITY OF MODEL FOR LOW SHEAR FLOW ANALYSIS IN DEVELOPING PLASTICIZED HTPB-BASED BINDER
}

\author{
Afni Restasari*, Luthfia Hajar Abdillah, Retno Ardianingsih, \\ Bagus Wicaksono, Rika Suwana Budi
}

National Institute of Aeronautics and Space (LAPAN), Jakarta, Indonesia

*Corresponding Author Email: afni.restasari@lapan.go.id

Received: 27 July 2020

Revised: 2 September 2020

Accepted: 22 October 2020

Online: 27 November 2020

Published: 31 December 2020

SPEKTRA: Jurnal Fisika dan Aplikasinya p-ISSN: 2541-3384 e-ISSN: 2541-3392

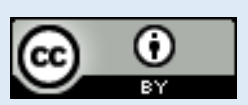

\begin{abstract}
In developing flow behavior of plasticized prepolymer as liquid content of composite solid propellant, zero shear viscosity (ZSV) is a critical parameter that Goh-Wan equation is developed to model it recently [1]. Thus, this work aims to analyze the compatibility of the Goh-Wan equation toward the liquid content of propellant, characterize it, and determine the limit. In this work, a varied flow behavior index was obtained by using Hydroxy terminated polybutadiene (HTPB) and HTPB-DOA (Dioctyl adipate) system with the variable of its concentration, pre-heating, and pre-stirring methods as samples. Viscosity was measured at 2, 3, 4, and $5 \mathrm{rpm}$ by using the disc spindle of Brookfield viscometer. For the minimum shear-rate investigation, as a limit of compatibility, other three sets of shear rates are applied, which are $0.6-5 \mathrm{rpm}, 1-5 \mathrm{rpm}$, and 1,5 - 5 rpm. By functioning Goh-Wan equation (model 1) and Power-Law (model 2), a model was categorized as compatible if yields lower value of ZSV than the first experimental measured viscosity $\left(\eta_{1 \mathrm{st}}\right)$. Characterization was determined by a graph of plotting percentage difference of ZSV obtained from models 1 and 2 towards the index of flow behavior. The $3 \%$ of the difference between ZSV obtained from model 1 and $\eta_{\text {st }}$ was set to be a minimum value for a set of applied shear-rate to be acceptable. It is reported that the Goh-Wan model is compatible with the liquid content of propellant and characterized by a perfect linear correlation. It is also found that a minimum applied shear rate of $1.5 \mathrm{rpm}$ is acceptable for model compatibility.
\end{abstract}

Keywords: zero shear viscosity, flow behavior, propellant, plasticizer 


\section{INTRODUCTION}

The composite solid propellant is a kind of rocket fuel that consists of solid and liquid contents. Solid content provides most of the energy needed to rocket reaches its height target. It includes aluminum and ammonium perchlorate as oxidation. It fills around $85 \%$ of the total mass of propellant. As high filled material, it is liquid content, a polymeric binder, that holds those microparticles with the network. This liquid content also plays a main role in manufacturing propellant as at first all components are mixed, forms a slurry, and cast into a certain shape of solid with specific complicated grain geometry [2-4].

Recently, research about case bonded propellant is more developed over free-standing propellant. Both are kinds of propellants based on their manufacturing way. In the freestanding method, the propellant is cast separately from the rocket motor. While in the case bonded method, the propellant is cast directly into the rocket motor. The preferences about case bonded propellant include its easiness to produce a big rocket as well as many rockets, higher performance, and higher stress tolerance $[3,5,6]$. However, concerning to flow of propellant slurry during casting, it has several problems.

Flow behavior is an unneglectable parameter to obtain a homogenous as well as physically non-defect propellant solid. Propellant slurry with poor flow is difficult to be mixed homogenously. As a result, for example, particles are more clustered in a certain part of propellant solid than other parts, and this condition has the potential to damage the rocket motor with more explosion in that part than others. The non-homogenous propellant slurry also causes the forming of voids, pores, and crazes, resulting in the same danger. In addition, designed grain geometry also can not be obtained smoothly with poor flow, making specific impulse (Isp) as a parameter of rocket performance far from prediction. Previous research has been performed to set an advantageous flow behavior parameter though it depends on the manufacturing technique $[3,7]$.

For viscosity, low value and slow rate of increasing viscosity are favorable to provide enough time for the process [8,9]. While for the pseudo-plasticity index, a value of $0.8-1$ is suitable for vacuum casting, and $0.6-1$ is for pressure casting [4]. To obtain those ideal parameters, usually, additive compounds include the variety of kind and amount, in liquid content as well as process parameter such as temperature and mixing speed are varied. To know the detailed effect of those variations, zero shear viscosity (ZSV) is a promises parameter [10].

$\mathrm{ZSV}$ is a constant value at zero shears or at very low shear conditions. It describes a constant value of flow resistance, independent of shear rates and comes from the structure of fluid, that is reached after heat dissipation [11,12]. For polymers such as Hydroxy terminated polybutadiene (HTPB), bases of propellant liquid content, it is reported to have a correlation with molecular weight, chain motion, and entanglements [13-15]. For polymer mixture, it indicates interaction among components as well as total entanglement formed [16]. It is reasonable for the system of HTPB-DOA. While a system involves dispersed particles such as propellant slurry, ZSV can be used to monitor flocculation, of which a low value indicates higher flocculation [12], [13]. In addition, to evaluate the network from certain liquid content with the same kind of particles, the low value of ZSV comes from the low surface tension of 
the network [19,20]. ZSV is also used as an indicator for the resistance of permanent deformation $[11,12]$.

$$
\begin{aligned}
& \eta=K \cdot \gamma^{n} \\
& \eta=K \cdot(\gamma+1)^{n G}
\end{aligned}
$$

Usually, the Power-law model, Equation 1, is used to obtain a value of ZSV roughly as a value of $\mathrm{K}$ by arranging it into logarithmic correlation. In those equations, $\gamma$ is the shear rate, $\eta$ is viscosity, and $\mathrm{n}$ is flow index with $\mathrm{n}=\mathrm{m}+1$. However, Goh E. G and Wan Nik W. B reported a more accurate equation to obtain ZSV, which is EQUATION 2. In those equation, nG is power constant $[1,21]$. Concerning this reliability, it is worth knowing the compatibility of the Goh-Wan equation toward the liquid content composition of propellant and characterizes its compatibility.

Recently, not focusing on curing agent, developed liquid content composition is HTPB-DOA system of which DOA plays a role as the plasticizer. The effects on flow behavior are reported. It is reported that the addition of DOA decreases the viscosity of both liquid content and slurry propellant, also longer processability time of slurry propellant [8], [9]. In addition, increasing DOA content increases the strength of shear thickening of the HTPB-DOA system as well as decreasing its general ZSV [22]. As in publications of Goh E. G and Wan Nik W. B did not cover a wide variety of shear-thickening liquid [1,21], exploring the Goh-Wan model on shear thickening of HTPB-DOA system is valuable.

However, in the latest publication, the range of $\mathrm{ZSV}$, which is $60-32 \mathrm{P}$, is determined by the Power-law model, not Goh-Wan education. Moreover, values of $n$ are only around 1.05-1.1, which is almost similar to each other, not sufficient for characterizing model compatibility [22]. Therefore, by adding more various value of $n$ of the liquid content of propellant, this research aims to analyze the compatibility of the Goh-Wan model towards liquid content of propellant and its characterization as well as determine the limits of its application.

\section{METHOD}

In this work, HTPB as prepolymer and HTPB-DOA as plasticized prepolymer were the samples. HTPB is produced by Dalian chlorate, China. The specifications of HTPB include molecular weight of $2300-2800$, a hydroxyl value of $0.81-1.0 \mathrm{mmol} / \mathrm{g}$, a polydispersity of 2.5 , and a hydroxyl number of $47.1 \mathrm{mmKOH} / \mathrm{g}$.

In order to obtain a varied flow behavior index, effects of temperature, mixing, and plasticizer content are concerned. Mixing was conducted by using IKA Mechanical stirrer with anchor type stirrer. Detail of the samples was described in TABLE 1. 
TABLE 1. Samples

\begin{tabular}{llll}
\hline Group & Code & Materials & Treatment \\
\hline A & A $^{*}$ & HTPB, DOA 5\% & Mixed at 60 rpm for 3 minutes \\
& B $^{*}$ & HTPB, DOA 10\% & Same as A* \\
& C $^{*}$ & HTPB, DOA 15\% & Same as A* \\
& D $^{*}$ & HTPB, DOA 20\% & Same as A* \\
E & HTPB & - \\
& F & HTPB & Heated at $40^{\circ} \mathrm{C}$ during viscosity \\
& & measurement \\
& G & Mixed at 60 rpm for 5 minutes, heated at \\
& HTPB, DOA 10\% & $40^{\circ} \mathrm{C}$ during viscosity measurement \\
& I & HTPB, DOA 20\% as G & Same as G \\
\hline
\end{tabular}

*Published data in Restasari et al. 2019 [22]

Viscosity measurements were performed by using Brookfield RVT Viscometer disc spindle 02 and a standard cup of which the instruments were reported to be suitable for low-shear viscosity measurement [23]. Applied rotational speeds $(N)$ were 2, 3, 4, and $5 \mathrm{rpm}$. Regarding instrument specification, those speeds were converted into shear rate $(\gamma)$ according to the method of P. Mitschka, J.L Briggs, and J.F Steffe through flow in FIGURE 1 of which $k_{\alpha \sigma}$ is a function of spindle number and $C$ is a constant based on viscometer mode. For Brookfield RVT viscometer spindle $02, k_{\alpha \sigma}$ is $0.119 \mathrm{~Pa}$, and constant $C$ is 1 . While, dial reading represents percent torque and value of $k_{N_{\gamma}}$ based on the value of obtained slope (n) [24], [25].

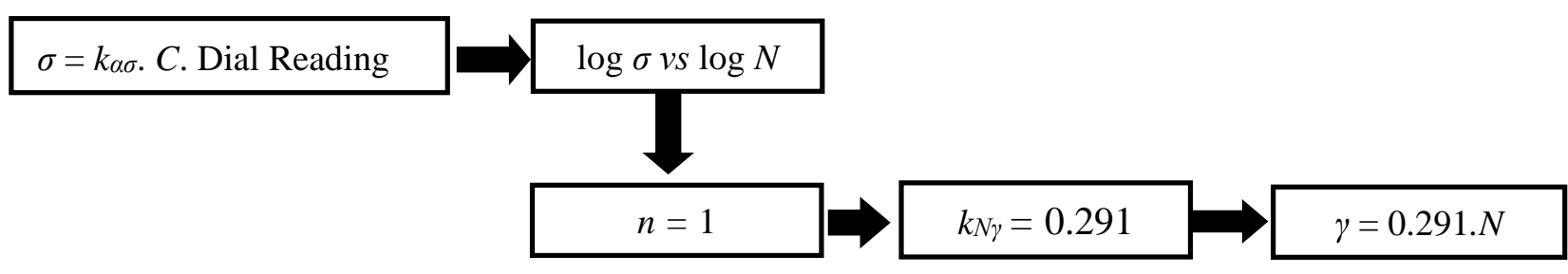

FIGURE 1. Method of converting $N$ into $\gamma$

FIGURE 2 describes the method to determine the compatibility of the model based on Equation 1 and 2 of which ZSV were obtained by extrapolating curves [1], [21], [23]. The requirement for a compatible model is a reliable value of ZSV of which ZSV is lower than the first experimental viscosity. The character of the use of a compatible model on samples was determined by plotting $\% \triangle \mathrm{ZSV}$ based on Equation 3 towards $n$ from the Power-Law model of samples. While in determining the limit of using the compatible model, 4 sets of shear rates were applied; set 1 for $0.6-5 \mathrm{rpm}$, set 2 for $1-5 \mathrm{rpm}$, set 3 for $1,5-5 \mathrm{rpm}$, and set 4 for $2-$ $5 \mathrm{rpm}$. Those sets were used to obtain $\% \triangle \mathrm{ZSV}_{\text {comp }}$ according to Equation 4 of which $\eta_{1 \mathrm{st}} \exp$ is measured viscosity at the lowest shear rate applied, and it was used for samples A - D.

$$
\begin{aligned}
& \% \triangle \mathrm{ZSV}=\left(\left(\mathrm{ZSV} \text { Power Law }-\mathrm{ZSV}_{\text {Goh-Wan }}\right) / \mathrm{ZSV} \text { Power Law }\right) .100 \% \\
& \% \triangle \mathrm{ZSV}_{\text {comp }}=\left(\left(\eta_{1 \text { st experimet }}-\mathrm{ZSV}_{\text {comp }}\right) / \eta_{1 \text { st exp }}\right) .100 \%
\end{aligned}
$$




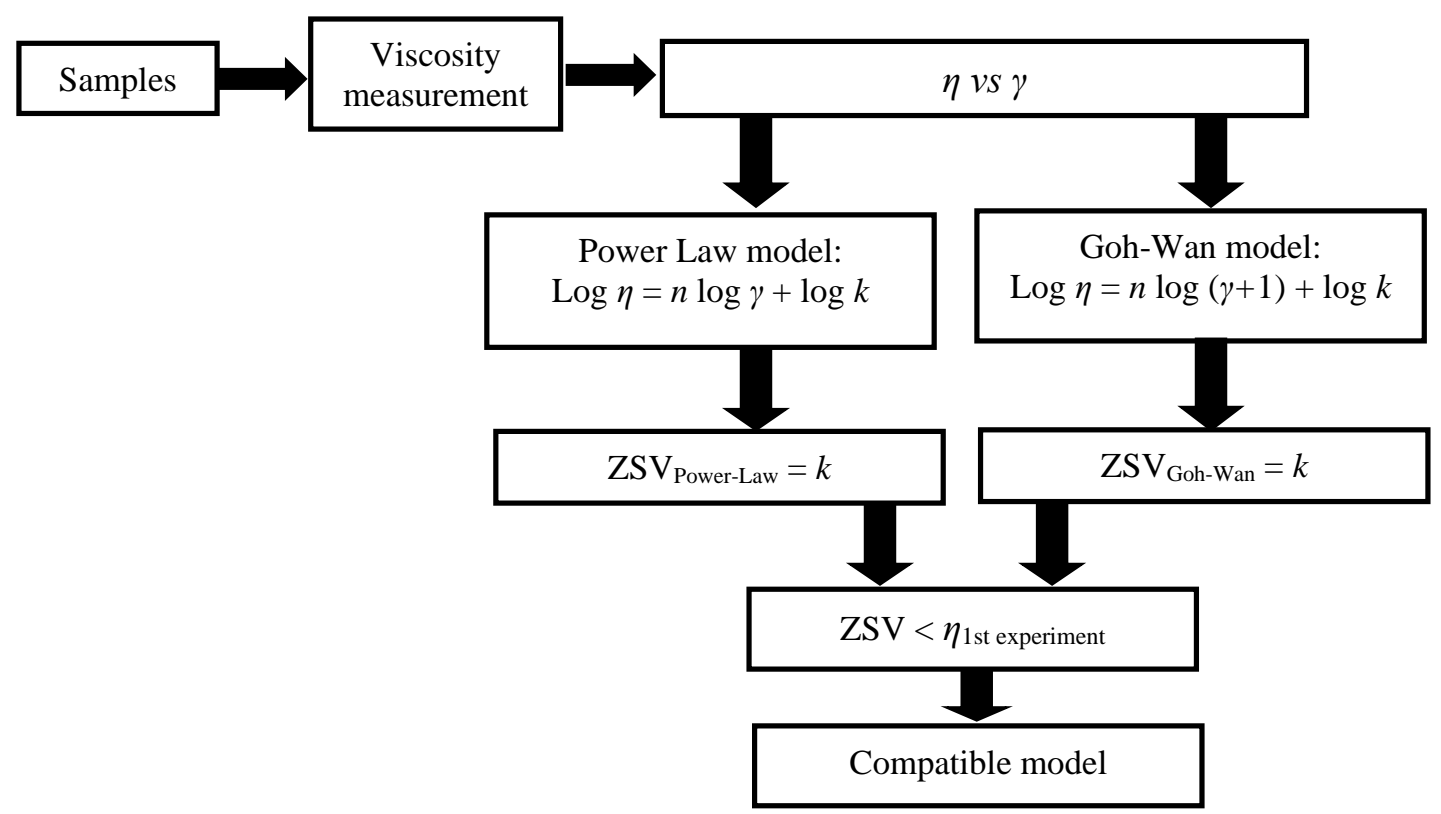

FIGURE 2. Method to determine the compatible model.

\section{RESULT AND DISCUSSION}

\section{Compatibility of viscosity model towards Group A}

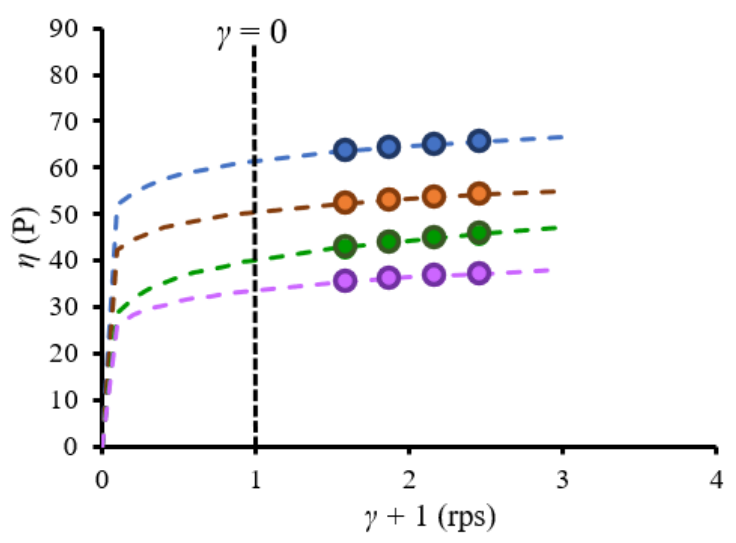

(a)

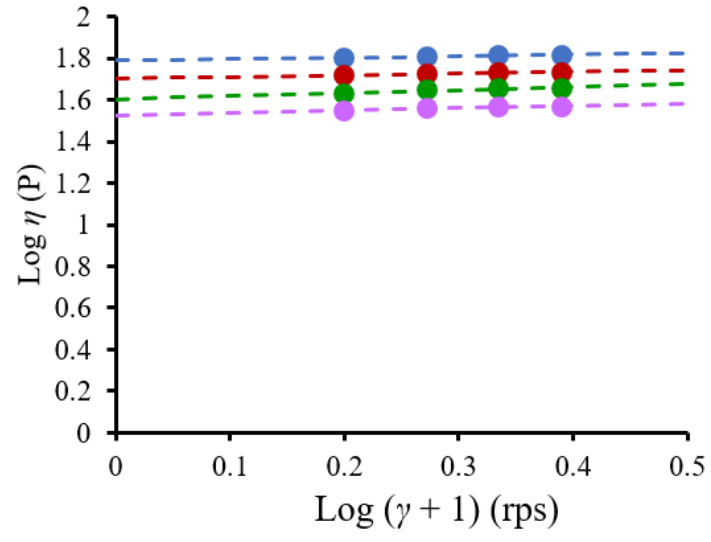

(b)

FIGURE 1. (a) Plotting (shear-rate +1 ) towards viscosity following the Goh-wan model where filled marks are for experimental values and unfilled marks are for plotted values. Color of blue, light brown, green, and purple are for samples of A - D, respectively. (b) Logarithmic graph of the graph (a).

Group A is a set of special samples about the effect of DOA concentration from publication paper [22]. The novelty of this paper towards that past publication is the use of the Goh-Wan model, as shown in FIGURE 1 to obtain accurate ZSV that is shown as an unfilled mark in FIGURE 2. 
The shapes of curves in Figure 1a are slightly different from others. As a consequence, slopes in linear correlation in logarithmic curves of samples A - D, Figure 1b, are very similar. This similarity obtained by using the Goh-Wan equation is also found when using the Power-Law model, resulting in narrow range values of $n$ [22], not sufficient to analyze the compatibility of the Goh-Wan model.

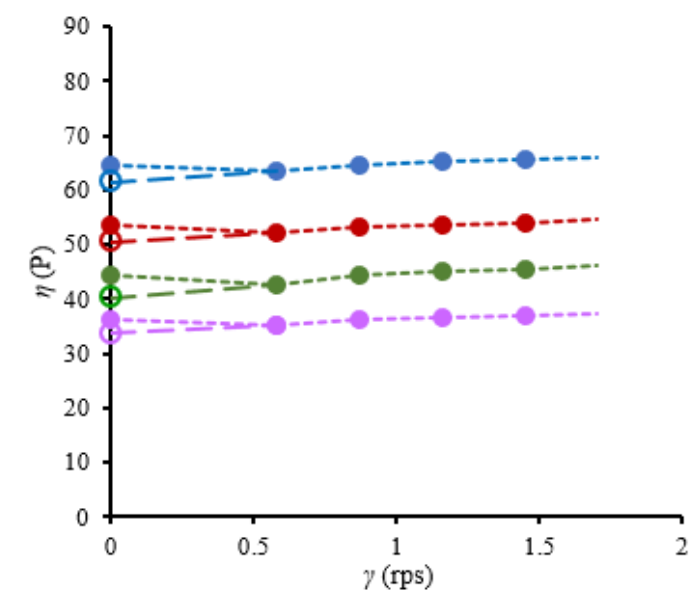

FIGURE 2. Viscosity against shear rates of which unfilled mark is ZSV plotted based on Goh-Wan Model. Color of blue, light brown, green, and purple are for samples of A - D respectively.

FIGURE 2 ultimately shows the difference value of ZSV obtained by using the Power-Law model and Goh-Wan equation. For all samples, it can be seen clearly that ZSV obtained from the Goh-Wan equation are reasonable because its value is lower than the first measured viscosity at around $0.5 \mathrm{rps}$. This compatibility predicts that the HTPB-DOA system is a generalized Newtonian fluid that can have a Newtonian plateau in the high shear rates region [1].

\section{Compatibility of viscosity model towards Group B}

In order to complete $n$ values of Group A samples, Group B is prepared by using the effect of temperature and mixing. FIGURE 3 shows plotted curves of viscosity towards shear-rate, and it shows that all samples have a slightly sheer thickening behavior of which viscosity increase with the increase of shear rate [22]. 


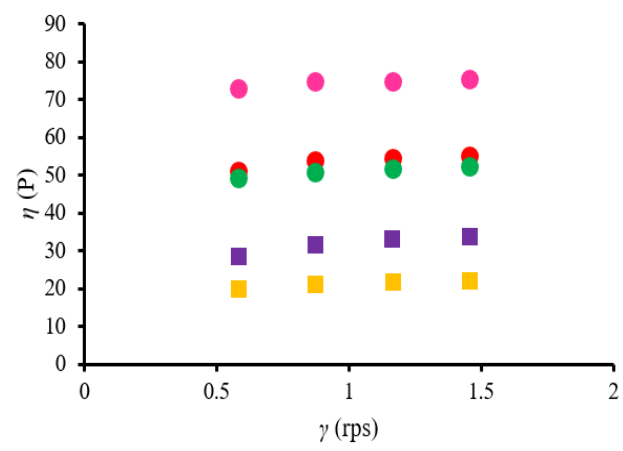

FIGURE 3. Viscosity against shear rates. Color of pink, red, green, purple, and light brown are for samples of E - I, respectively.

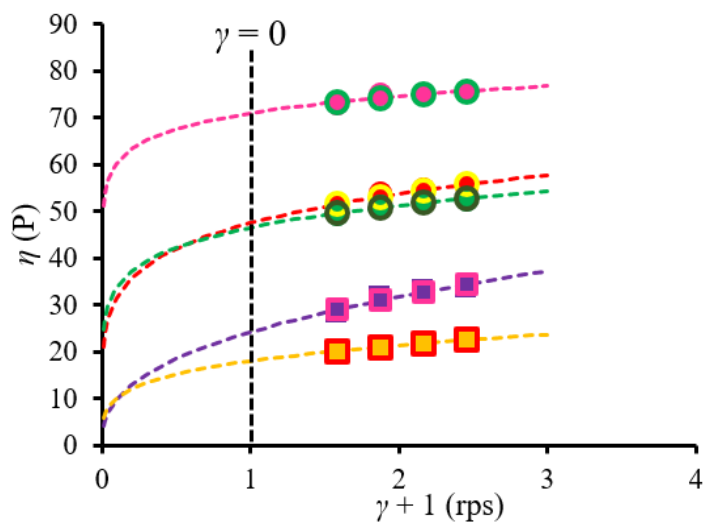

(a)

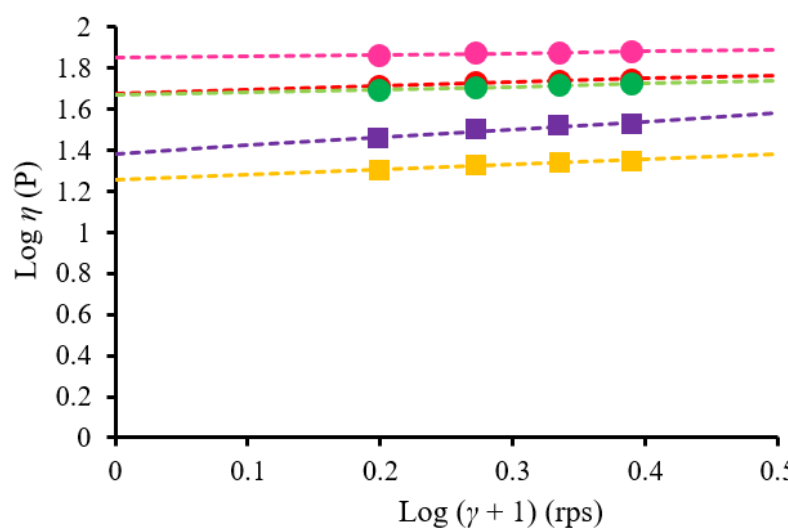

(b)

FIGURE 4. (a) Plotting (shear-rate +1 ) towards viscosity following the Goh-wan model where filled marks are for experimental values and unfilled marks are for plotted values. Circles are for the HTPB system, and squares are for the HTPB-DOA system. For filled marks, pink, red, green, purple, light brown are for samples of E - I, respectively. For unfilled marks, green, yellow, dark green, pink, red is for samples of E - I, respectively. (b) The logarithmic curve of (a).

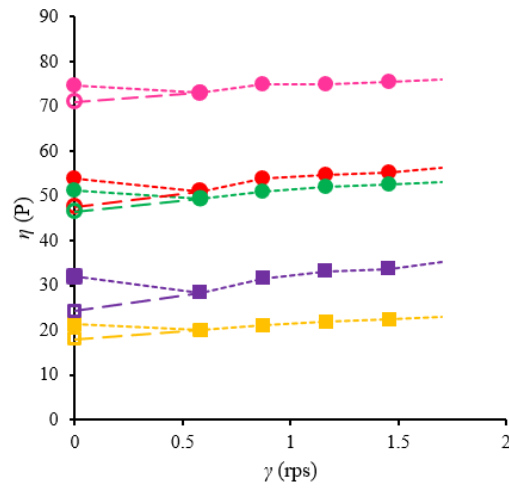

FIGURE 5. Viscosity against shear rates of which unfilled mark is ZSV plotted based on Goh-Wan Model. Circles are for the HTPB system, and squares are for the HTPB-DOA system. Colour of pink, red, green, purple, light brown are for samples of $\mathrm{E}-\mathrm{I}$ respectively.

Distinguished from Group A samples, Group B shows more varied values of viscosity, $\mathrm{n}$, and Goh-Wan plotted ZSV, accomplishing its aim of preparation. Regarding the preparation 
method, heating applied in sample $\mathrm{F}$ and heating plus mixing applied in sample $\mathrm{G}$ have no significant difference. However, it has the obvious effect of decreasing viscosity, and GohWan plotted ZSV of HTPB. On the other side, unlike sample B and D in Group A samples, with pre-heating and pre-mixing, the twice concentration of DOA (sample $\mathrm{H}$ and I) exhibit clear, distinguishable values of n.although the value of Goh-Wan plotted ZSVs are only slightly different with a range only 20 - 25 Poise, shown in FIGURE 5.

Regarding the reliability of the Goh-Wan equation, same as Group A, all values of ZSV in Group B samples are reasonable, neglecting different applied procedures in its preparation. It can be caused by its structure of which HTPB and DOA are basically a hydrocarbon, similar with samples used in developing Goh-Wan equation which is gelex water-based fluid, bentonite in gel-drilling fluid, soy, corn, canola and coconut oils [1], [21], [22], [26]. Therefore, all data of Group A and B can be used to characterize the Goh-Wan equation toward the liquid content of propellant.

\section{Characterization of Flow Behavior based on Goh-Wan Model}

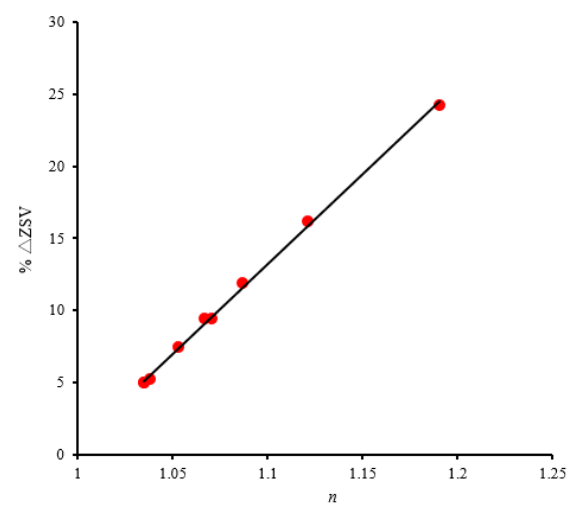

FIGURE 6. Value of $n$ from Power-Law model vs. $\% \triangle \mathrm{ZSV}$.

It is known that the value of ZSV, $\mathrm{K}$ value in EQUATION 1 and 2, depends on the value of $\mathrm{n}$ as a material character [27]. Therefore, a graph of K vs. $n$ can be a character of a material. However, to be deeper, the value of $\mathrm{K}$ can be replaced by $\% \triangle \mathrm{ZSV}$, which is the percentage of (ZSVPower-Law - ZSVGoh-Wan) over ZSVPower-Law, and its graph is shown in FIGURE 6.

In FIGURE 6, all values of $\mathrm{n}$ and $\% \triangle \mathrm{ZSV}$ from Group $\mathrm{A}$ and $\mathrm{B}$ samples, neglecting the compound composition, pre-heating, and pre-mixing, are plotted together as liquid content of propellant. As shown in FIGURE 6, those two parameters exhibit a perfectly linear correlation with the equation of $\% \triangle \mathrm{ZSV}=124.74 \mathrm{n}-123.09$. For practical use to convert ZSV from the Power-Law model into ZSV from the Goh-Wan model, it is re-written as ZSVGoh-Wan $=$ ZSV Power-Law - ((124.74 n - 123.09) (ZSV Power-Law: 100)). This linear correlation supports DOA as a compatible plasticizer for HTPB because of similar solubility parameters between DOA and HTPB [22]. It also supports the compatibility of the Goh-Wan equation for the liquid content of propellant. On the other hand, regarding the range of $n$, it shows that the more liquid 
content tends to be shear thickening, the more difference between ZSVPower-Law and ZSVGoh-Wan. It is shown briefly for sample H in FIGURE 5.

\section{Limitation on Applied Shear Rate}

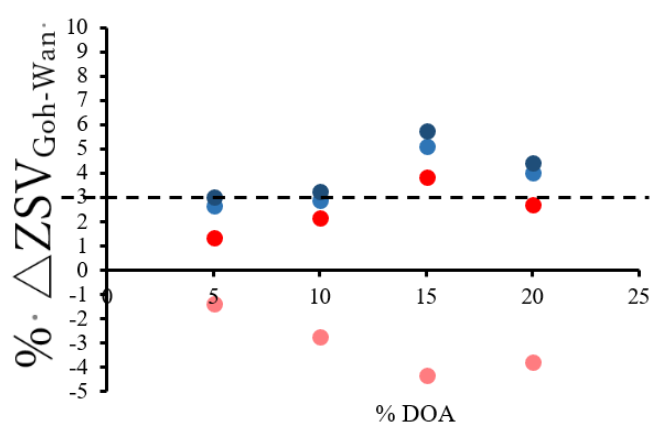

FIGURE 7. (\% $\triangle \eta 1$ st exp and ZSV) vs. \%DOA by applying shear rate set 1 (pink), set 2 (red), set 3 (blue), and set 4 (dark blue).

As a mathematical model, the range of input variable has the potential to limit the compatibility of the model toward a certain material, for example, in the fluidization model of alumina particles of which fluid velocity affects the simulated minimum condition of fluidization [28]. Therefore four sets of applied shear rates are performed, resulting in FIGURE 7. By setting a y-axis value of $3 \%$ as the border, only set 3 and 4 that are acceptable, resulting in $1.5 \mathrm{rpm}$ as the minimum shear rate that is supposed to be applied.

\section{CONCLUSION}

In this work, compatibility, characterization, and limitation of the viscosity model were investigated for liquid content of propellant, HTPB, and DOA. Variation of the samples involves mixing and heating prior to viscosity measurement and also the concentration of DOA. It is reported that the Goh-Wan model resulting in a more reasonable value of zero shear viscosity than the Power-Law model, compatible with the liquid content of propellant. Its compatibility is identified by a perfect linear correlation with equation of $\% \triangle \mathrm{ZSV}=124.74$ $n$ - 123.09. By limiting the difference between the first measured viscosity and $\mathrm{ZSV}_{\text {Goh-Wan, of }}$ which $3 \%$ is the minimum value to be accepted, it is found that the minimum applied shear rate is $1.5 \mathrm{rpm}$.

\section{ACKNOWLEDGEMENT}

This work is funded by LAPAN. The authors would like to thank Kendra Hartaya for guidance during this work.

\section{REFERENCES}

[1] E. G. Goh and W. B. Wan Nik, "A Generalized Model for Viscosity as a Function of Shear Rate,” ARPN J. Eng. Appl. Sci., vol. 13, no. 9, pp. 3219-3223, 2018.

[2] A. DAVENAS, “Composite Propellants,” Pergamon Press Ltd, 1993. 
[3] B. Thiyyarkandy et al., "Numerical studies on flow behavior of composite propellant slurry during vacuum casting," J. Aerosp. Technol. Manag., vol. 4, no. 2, pp. 197-203, 2012.

[4] G. Dombe et al., "Pressure casting of composite propellant," Indian J. Chem. Technol, vol. 15, pp. 420-423, 2008.

[5] Sutrisno, "Pembuatan Dan Analisis Kinerja Sistem Thermal Insulation Pada Motor Roket Yang Menggunakan Propelan Case-Bonded," J. Teknol. Dirgant., vol. 9, no. 2, pp. 93-101, 2012.

[6] M. Johannsson, "Optimization of Solid Rocket Grain Geometries," Royal Instititute of Technology (KTH), 2012.

[7] S. Remakanthan et al., "Analysis of Defects In Solid Rocket Motors Using X-Ray Radiography," e-Journal Nondestruct. Test, vol. 20, no. 6, 2015.

[8] A. Restasari and L. H. Abdillah, "Pengaruh Dioctyl Adipate Terhadap Pot-Life Proopelan Berformula AP Trimoda," in Prosiding SIPTEKGAN XXI, pp. 314-322, 2017

[9] Sutrisno, "Pengaruh Penambahan Plasticizer DOA terhadap Kinerja Propelan HTPB," in Prosiding SIPTEKGAN XIV, pp. 123-127, 2010.

[10] T. Standau et al., "Evaluation of the Zero Shear Viscosity, the D-Content and Processing Conditions as Foam Relevant Parameters for Autoclave Foaming of Standard Polylactide (PLA)," Materials (Basel), vol. 13, no. 1371, 2020.

[11] F. Morea, J. O. Agnusdei, and R. Zerbino, "Comparison of methods for measuring zero shear viscosity in asphalts," Mater. Struct, vol. 43, pp. 499-507, 2010.

[12] M. Liao and J. Chen, "Zero Shear Viscosity of Bitumen-Filler Mastics," J. Mater. Civ. Eng., vol. 23, pp. 1672-1680, December 2011.

[13] S. J. Dalsin, M. A. Hillmyer, and F. S. Bates, "Molecular Weight Dependence of ZeroShear Viscosity in Atactic Polypropylene Bottlebrush Polymers," Am. Chem. Soc. Macro Lett, vol. 3, pp. 423-427, 2014.

[14] Dynisco, (2019). The Relationship Between Molecular Polymer Weight and Zero Shear Viscosity [Online]. Available:

https://www.azom.com/article.aspx?ArticleID=17996 P.

[15] K. Li and G. Matsuba, "Effects of relaxation time and zero shear viscosity on structural evolution of linear low-density polyethylene in shear flow," J. Appl. Polym. Sci, pp. 19, 2017.

[16] S. Zhang, F. Li, and J. Yu, "Rheological Properties of Cellulose-NaOH Complex Solutions : From Dilute to Concentrated States," Cellul. Chem. Technol, vol. 45, no. 56, pp. 313-320, 2011.

[17] V. Samavati et al., "Application of Rheological Modeling in Food Emulsions," Iran. J. Chem. Chem. Eng, vol. 31, no. 2, pp. 71-83, 2012.

[18] A. Restasari, R. S. Budi, and K. Hartaya, "Pseudoplasticity of Propellant Slurry with Varied Aluminium Content for Castability Development," J. Phys. Conf. Ser, vol. 1005, no. 1, 2018. 
[19] M. H. Allouche et al., "Journal of Non-Newtonian Fluid Mechanics Experimental determination of the viscosity at very low shear rate for shear thinning fluids by electrocapillarity," J. Nonnewton. Fluid Mech, vol. 215, pp. 60-69, 2015.

[20] L. H. Abdillah, "Penelitian Swelling Prepolimer HTPB-TDI Sebagai Penjajagan Peningkatan Solid Loading Pada Formulasi Propelan," in Teknologi Pesawat Terbang sebagai Mitra Pengembang Teknologi Roket dan Satelit Nasional, Jakarta: Indonesia Book Project, pp. 359-374, 2015

[21] S. G. E. Giap and A. Amran, "Dynamic viscosity as a function of shear rate: The comparison of established rheological models with the newly derived rheological model for the estimation of zero- and infinite-shear rate viscosity of vegetable oils," J. Teknol, vol. 54, pp. 111-120, January 2011.

[22] A. Restasari et al., "Pengaruh Dioctyl Adipate Terhadap Sifat Rheologi HTPB Terplastisasi," J. Teknol. Dirgant, vol. 16, no. 2, pp. 139-149, 2018.

[23] R. P. Chhabra and J. F. Richardson, "Non-Newtonian Flow and Applied Rheology," 2nd ed. Butterworth-Heinemann: Elsevier, 2008.

[24] P. Mitschka, "Simple conversion of Brookfield R.V.T. readings into viscosity functions," Rheol. Acta, vol. 21, no. 2, pp. 207-209, 1982.

[25] J. L. Briggs and J. F. Steffe, "Using Brookfield data and the Mitschka method to evaluate power law foods," J. Texture Stud, vol. 28, no. 5, pp. 517-522, 1997.

[26] A. Dey et al., "Effect of Microstructure on HTPB Based Polyurethane (HTPB-PU)," J. Mater. Sci. Eng. B, vol. 5, no. 3-4, pp. 145-151, 2015.

[27] H. Yamaguchi, "Engineering Fluid Mechanics," Netherland: Springer-Verlag/Wien, 2008.

[28] A. Rudiawan et al., "Fluidization of A Bed of Solid Particles in A Two Dimensional Vertical Box," SPEKTRA J. Fis. dan Apl, vol. 4, no. 2, pp. 73-80, 2019. 
